\title{
Psicanálise, Clínica e Universidade: Impasses e Possibilidades
}

\author{
Carlos Henrique Kessler ${ }^{*}$ (D) \& Thiago Pereira da Silva (1) \\ Universidade Federal do Rio Grande do Sul, Porto Alegre, RS, Brasil
}

\begin{abstract}
RESUMO - O presente artigo toma lugar no campo problemático da inserção da psicanálise no contexto universitário, seus impasses e possibilidades. Posicionamo-nos desde uma pergunta pela função possível, talvez eventual, da universidade na transmissão da psicanálise e na formação do analista. Procuramos pensá-la a partir do cenário da prática clínica referida à psicanálise na universidade, tomando como balizas os efeitos recolhidos de nossa experiência de prática e supervisão, bem como debate institucional, em uma clínica-escola vinculada à universidade. Partindo de uma revisão de operadores conceituais que nos permite situar os problemas em jogo, dando espaço ao diálogo com os aportes dados por colegas inseridos no contexto brasileiro, buscamos apontar algumas contribuições para este campo de reflexão.
\end{abstract}

PALAVRAS-CHAVE: psicanálise, clínica, universidade, clínica-escola

\section{Psychoanalysis, Clinic, and University: Impasses and Possibilities}

\begin{abstract}
This article takes place in the problematic field regarding the inclusion of psychoanalysis in the context of the university, along with its impasses and possibilities. Our position is defined by the question pertaining university's possible role in the transmission and training in psychoanalysis, based on the effects derived from our experience of clinical practice and supervision as well as institutional debates taken place in a university school clinic. We seek to introduce contributions to this field through a review of conceptual operators and expand a line of dialogue related to our peers' work on the Brazilian context.
\end{abstract}

KEYWORDS: psychoanalysis, clinic, university, school-clinic

\section{INTRODUÇÃO}

O debate sistemático acerca das relações entre psicanálise e universidade tem-se constituído, já há alguns anos, como importante campo de reflexão e de impasse. Trata-se de uma fronteira sensível e não raro polêmica, composta de tensionamentos plurais oriundos do que se apresenta, ao menos em um primeiro momento, como uma disparidade radical entre os modelos e lógicas de formação vigentes nos campos em questão. No plano assim composto, teríamos a sustentação clássica do tripé da formação do psicanalista por um lado (análise pessoal, estudo e supervisão), proposto por Freud (1976) e até hoje defendido pelas instituições analíticas, e o modelo universitário pelo outro (ensino, pesquisa e extensão), orientado a partir da composição de um conjunto mínimo de conhecimentos necessários a serem adquiridos, em certa ordem, para a obtenção de um diploma, visando o exercício profissional. Entra em questão, nesse contexto, a pergunta pelo lugar do sujeito e de seu desejo nos diferentes modelos e percursos de formação. Dessa forma, dada a disparidade apontada, não raros são os psicanalistas que problematizam essa relação.

Jean Allouch, por exemplo, afirmará em entrevista que "Não há nenhuma possibilidade da psicanálise na universidade", agregando: "Não encontro nenhum sentido em que haja uma aula sobre Lacan, em que haja uma aula sobre algum conteúdo da psicanálise" (Orejuela \& Salazar, 2009, p. 192, tradução livre). Esse enunciado será justificado pelo psicanalista em função da posição que seria a característica do professor, avessa ao não saber, em que este "sempre teria que dizer algo sobre alguma coisa que se lhe pergunte" (Orejuela \& Salazar, 2009, p. 192, tradução

* E-mail: carloshkessler@yahoo.com.br

- Submetido: 24/05/2019; Revisado: 12/11/2019; Aceito: 13/08/2020. 
nossa). Essa dinâmica, que Allouch refere ao discurso universitário, restringiria a possibilidade e o interesse da psicanálise nesse contexto, por ser uma que obstrui seu percurso. Semelhante apontamento parece ser feito por Lacan (1992) quando, ao comentar a tese de Lemaire (1979) - para a qual escreve inclusive um prefácio -, indica que seu ensino não se presta a um trabalho acadêmico. Temos neles um argumento que, em sua radicalidade, lança elementos que procuraremos trabalhar ao longo deste artigo, apresentando também autores que, compartilhando da mesma matriz crítica, apresentam posições distintas frente ao problema.

Particularmente no que tange à experiência na universidade brasileira, o limiar que evocamos não se apresenta de forma absoluta, unívoca e sem sutilezas. Não apenas é fato, como apontam Coutinho et al. (2013), que a psicanálise tem sua inserção oficial, curricular, na universidade brasileira desde a década de 1950, como também se observam diversos pontos de encontro anteriores. Dias (2003) aponta haver uma proliferação da teoria psicanalítica nos currículos dos cursos de Psicologia, Medicina e nos programas de pós-graduação que se destinam ao ensino da psicanálise. Para Fontenele (2006), a presença dos psicanalistas na universidade seria uma realidade, o que não impede que se esbarre permanentemente em uma série de obstáculos em função das diferenças entre os campos da psicologia e da psicanálise. O próprio estudo de Coutinho et al. (2013), a partir de teses e dissertações que versariam sobre este tema, aponta para o fato aparentemente paradoxal de que o debate acerca das relações e dos impasses entre psicanálise e universidade encontra possibilidade e um lugar especial no próprio contexto universitário. Importante ainda ressaltar a importância que Roudinesco (2000) identifica na universidade para a psicanálise no contexto brasileiro. Para a autora, seriam as universidades, mais do que as instituições psicanalíticas, que preservariam a vanguarda do freudismo no Brasil, inserida especialmente nos departamentos de psicologia.

Cabe ressaltar que não é unânime o reconhecimento dessa relação como ponto de tensão, dado o posicionamento pragmático de certas correntes de psicanalistas no âmbito da universidade. Assim, julgamos justa a pontuação de que o reconhecimento e o debate acerca dos impasses presentes no limiar psicanálise/universidade encontram fortes marcas de uma vertente mais alinhada à posição lacaniana - na qual nos situamos. Isso parece-nos, por uma série de fatores, não ser ao acaso. Primeiramente, pelo fato de a universidade ter sido local privilegiado no percurso do ensino de Lacan, especialmente a partir da década de 1960, quando ela se torna sede de seus seminários. Segundo, pela tematização direta que ele posteriormente faz da universidade em seu trabalho teórico, na figura de sua teoria dos discursos (que veremos a seguir). Terceiro, por termos no Brasil, talvez por motivos não indiferentes aos dois anteriores, uma ocupação considerável do espaço universitário por psicanalistas lacanianos. Como indica Fonteles (2015), há no contexto brasileiro um "predomínio freudo-lacaniano" (p. 125) no que tange à produção acadêmica que se insere ou dialoga com a psicanálise ${ }^{1}$. Esse aparente predomínio no espaço universitário não nos parece inconsequente nos processos de reflexão e pesquisa sobre as particularidades dessa relação. Buscamos aqui, então, nos ocupar deste impasse, reconhecendo-o, mas sem subscrever de imediato a um anúncio da impossibilidade.

Temos como ponto pacífico o fato de que o ensino universitário não esgota a formação analítica nem garante sua transmissão - isto, inclusive, já foi posto claramente por Freud (1976), em seu texto "Sobre o Ensino da Psicanálise na Universidade". Todavia, parece-nos deletério que disso se extraia como consequência a priori a suposição de que estes campos operariam apenas por disjunções excludentes - posição compartilhada também por Pinheiro e Darriba (2010). Posicionamo-nos desde uma pergunta pela função possível, talvez eventual, da universidade na transmissão da psicanálise e na formação do analista, ou melhor, pelas vias possíveis de transmissão da psicanálise no contexto universitário. Procuraremos pensá-la, neste texto, a partir do cenário da clínica referida à psicanalise na universidade, tomando como balizas os efeitos recolhidos de nossa experiência de prática e supervisão, bem como debate institucional, na Clínica de Atendimento Psicológico (CAP) da Universidade Federal do Rio Grande do Sul (UFRGS).

Tendo a Clínica-Escola como horizonte deste artigo, partiremos de uma breve revisão de operadores conceituais que nos permitam situar a questão da práxis psicanalítica em suas relações com a universidade. Dado que as relações sobre as quais refletimos se dão no cenário brasileiro, julgamos de fundamental importância dialogarmos com os aportes dados por colegas que neste se inserem e que dele tomam interrogantes. Por fim, a partir de nossa experiência e dos efeitos que dela extraímos, buscamos apontar algumas contribuições para esse campo de reflexão.

1 Das 1.075 teses coletadas pelo estudo, produzidas entre 1987 a 2012 , ao passo que 421 citam nominalmente Freud em seus resumos, 331 citam Lacan. O terceiro lugar em citações, Winnicott, é referido apenas 87 vezes. A autora especifica que há resumos que não referem nominalmente quaisquer psicanalistas. 


\section{PONTOS DE PARTIDA}

Como mencionamos, apesar dos matizes específicos que compõem sua problemática contemporânea, o tema aqui proposto não escapa inclusive a Freud - tendo já sido abordada explicitamente em 1919 -, com o que poderíamos afirmar que tal preocupação acompanha-nos desde os princípios da psicanálise. No texto referido, Freud (1976) não subscreve a uma recusa imediata da possibilidade de inserção da psicanálise no ensino universitário, apontando ainda para seu possível interesse, ao mesmo passo, todavia, que sustenta não se tratar de uma completa adesão "A inclusão da psicanálise no currículo universitário seria sem dúvida olhada com satisfação por todo psicanalista. Ao mesmo tempo é claro que ele pode prescindir completamente da universidade sem qualquer prejuízo para si” (Freud, 1976, p. 217).

Vemos delinear-se neste texto algo da faceta inicial da problemática em jogo, evidenciando-se certa tensão concernente, quando é escrito, à aceitação ou não, na universidade, da nova disciplina que se desenhava. Poderíamos ler, nesse gesto de prescindir da universidade, tanto um efeito de necessidade decorrente do rechaço inicial ao qual é submetida a psicanálise, o que é apontado por Freud no texto, como também uma marca da diferença entre os processos de formação envolvidos. À psicanálise, bastaria o "tripé" para a formação do analista, vindo sua inclusão no ambiente universitário como algo "a mais" - e em seu tom o interesse que transpassa parece ser mais externo do que interno à psicanálise. Cabe ainda destacar que não figuram no escrito muitos elementos que nos permitam pensar mais amplamente as intercorrências desta eventual inserção. Que a formação psicanalítica per se prescinda da universidade, e que esta não esgote aquela, argumentos de Freud, isso não nos diz muito das modalidades possíveis, ou impossíveis, de relação entre elas. Ressaltaríamos, contudo, seu apontamento de que, nesta inserção, seria suficiente ao aluno "que ele aprenda algo sobre psicanálise e que aprenda algo a partir da psicanálise" (Freud, 1976, p. 220). Restaria, portanto, a questão de como se aprenderia sobre e a partir da psicanálise, tendo presente a colocação de Lacan - quando indagado a respeito do tornar-se analista a partir do ensino universitário - de que "a psicanálise não se transmite como qualquer outro saber" (Lacan, 1992, p. 188).

Nessa linha, a contribuição de Lacan nos fornece operadores-chave conceituais para a reflexão acerca das relações entre psicanálise e universidade, dos quais sublinhamos sua teoria dos quatro discursos (do mestre, da histérica, do universitário e do analista), desenvolvida especialmente no seminário 17 (Lacan, 1992). Nela, o autor intenta distinguir uma estrutura necessária no discurso que ultrapassaria as circunstâncias da palavra, caracterizando modalidades distintas de laço social. Nesse passo, propõe, a partir da estrutura da linguagem, o estabelecimento de certas relações fundamentais e estáveis entre elementos e lugares determinados, indo para além de enunciações particulares.

Caracterizando os quatro lugares de sua estrutura de discurso, temos a seguinte organização:

agente outro/trabalho

verdade produção/perda

Acima, à esquerda, fica o lugar do desejo, mais tarde situado também como o do agente, da ordem, do mandamento do discurso. É o lugar do elemento dominante, que ordena e serve assim para identificar qual seja o discurso em questão. Abaixo deste, a verdade do discurso, sempre encoberta; acima, à direita, a posição do Outro (posteriormente, também do trabalho); e, abaixo deste, a perda, forma de também nomear a produção. Esses lugares fixos serão ocupados por 4 elementos, dispostos em série, sempre na mesma ordem, independente de seus lugares: S1, o significante mestre; S2, o saber, bateria articulada dos significantes; $\$$, o sujeito barrado, dividido; e $a$, objeto causa de desejo e mais-degozar. Assim, Lacan (1992) vai propor sucessivos quartos de giro, alterando a posição dos elementos no sistema, o que vai constituir quatro possibilidades radicais de discursos (DM: discurso do mestre; DU: discurso universitário; DH: discurso da histérica; DA: discurso do analista).

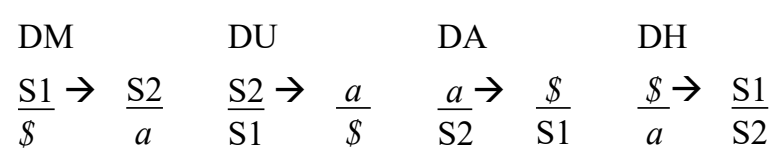

A exploração das possibilidades abertas por esta proposição nos permitirá refletir sobre nosso tema a partir das diferenças entre o discurso universitário e o do analista, especialmente no que concerne ao lugar ocupado pelo saber em cada um.

Tomemos a formulação do discurso universitário. Esse discurso faz surgir o S2 no lugar dominante, como um saber desnaturado de sua localização primitiva (S1). O mandamento que brota é "continua a saber sempre mais" (Lacan, 1992, p. 98). Saber o que seria a suposta verdade sobre os objetos, como tudo-saber/todo-saber (tout-savoir), não como um semidizer. Só que, na medida em que a verdade é um semidizer, ao falarmos algo, parte desse mesmo dizer se tornará obscuro. O imperativo do tout-savoir faz com que se possa supor prescindir de alguém que nos impulsione a saber. Sustenta-se, então, a ilusão de um saber em condição autônoma e independente. No discurso do analista, por outro lado, é o objeto $a$, enquanto causa do desejo, que está em posição de mandamento. $\mathrm{O}$ analista se oferece como ponto de mira para o desejo de saber do analisante, que assim, procurando saber sobre si, irá produzir os significantes de 
sua divisão. O saber, neste discurso, é posto a funcionar como verdade.

O discurso universitário vai ser apontado por Lacan (1992) como possuindo crescente pregnância na composição das relações sociais, ganhando lugar de destaque no contemporâneo. Diversos autores brasileiros, como mencionado anteriormente, apontarão para as dificuldades enfrentadas por aqueles que, tendo a psicanálise como horizonte de trabalho, se inserem nas universidades. Lo Bianco (2006a) posiciona o impasse da seguinte forma: em razão das características do discurso universitário, tomado como predominante nas universidades, a psicanálise se depararia com entraves ao sustentar neste contexto uma lógica de ensino que lhe seria avessa. Frente ao mandamento do tout-savoir do discurso universitário, a psicanálise responderia partindo do reconhecimento de sempre haver algo de irredutível ao saber:

"O analista (ou analisante) que também ensina nas universidades, ... não deixa de ser responsável pelo que da psicanálise comparece ou se vela em cada laço no qual ela é tomada. Seu ensino, portanto, não se dá sem a marca do saber que veicula... inconsciente, ... fragmentário, que não se totaliza... por não poder ser todo dito..." (Lo Bianco, 2006a, pp. 7-8)

Eis então a dificuldade com que se confrontam aqueles que, ensinando na universidade - um lugar em que se trabalha para saber -, se veem igualmente frente à implicação ética de visar a um sujeito do desejo, dada sua formação analítica -e, dessa forma, dirigir-se à sua divisão. Castro (2006) ressalta que não há ensino da psicanálise desvinculado de sua ética e de seus operadores. Subordinar o ensino da psicanálise ao discurso universitário implica que o ensinante esteja, necessariamente, sob um contrassenso ético. Lo Bianco (2006b) aponta outro problema que está em questão para aqueles que acreditam poder escolher se aproximar da psicanálise por intermédio do saber universitário: sempre que se depare com aquilo que é da ordem do irredutível, seu movimento imediato será, nos cursos universitários, o de tentar recuperá-lo por meio de um saber. Na mesma via, Darriba (2011) aponta que "para Lacan, é o discurso analítico que permite vislumbrar que algo se dirige ao impossível. Em contraste, a articulação do discurso universitário veste de impotência o que é da ordem de um impossível de saber." (pp. 301-2).

Nesse rastro, somos diretamente levados a pensar em como a inclusão da psicanálise traz consigo tensões nos diferentes campos que compõem o enodamento básico da estrutura universitária, para além do ensino. Destacaríamos aqui, a título de exemplificação, o campo da pesquisa, tomado frequentemente como atividade por excelência da universidade. Trata-se de uma problemática epistemológica de longa data (incluindo em si a histórica querela acerca o estatuto científico da psicanálise), da qual encontramos uma válida perspectiva em Lo Bianco (2003). Em uma ampla revisão das bases dos procedimentos investigativos em nossa disciplina, a autora apontará para a necessidade do estabelecimento de formas específicas de investigação que sejam apropriadas ao objeto específico que se constitui no campo da psicanálise - o sujeito do inconsciente. Lo Bianco e Sá (2006) ressaltarão que Freud teria fundado seu dispositivo clínico por ter admitido a impossibilidade de aceder aos dados positivos e obtidos em condições controláveis. Um ato que funda um dispositivo que vai se ocupar dos restos, do que não pode ser assimilado, daquilo que, do sujeito, opera como causa, que não se pode controlar, escapando do campo das ciências empíricas, onde o sujeito e seu ato ficam elididos. O reconhecimento desta especificidade, do espaço particular da psicanálise no campo das ciências, seria fundamental para possibilitar o desenvolvimento da pesquisa psicanalítica. Assinalaríamos, ainda, que a possibilidade de fazer operar e produzir a partir destas tensões encontra-se no cerne do que determinará o sucesso ou o fracasso da inserção da psicanálise no contexto universitário.

Dadas as diversas tensões que se apresentam, seguindo a linha do impasse entre os modelos de formação em discussão, Sbano (2004), a partir de um estudo criterioso, diferenciando o contexto universitário daquele de uma instituição psicanalítica, sustentará que é somente na segunda que se dará a formação do analista. Todavia, julgamos importante ressaltar que se por um lado não há como formar analistas na universidade, de outro, não há como evitar procurar lidar com esta demanda, na medida em que ela se apresente.

Cabe aqui também assinalar que a universidade não seria espaço de monopólio do discurso universitário, mesmo que tenha sido dali que Lacan se inspirou para propô-lo, o que não é para nada indiferente. Maurano (2006), por exemplo, insiste que nem tudo o que ocorre na universidade é integrante do discurso universitário, o qual, aliás, tem sua função e pertinência no contexto em que habita. Com isto, teríamos uma dupla formulação: não só e não-toda. O discurso universitário se encontraria vigente não só na universidade, bem como não-toda universidade é regida pelo discurso universitário. O discurso, em Lacan, como dissemos, é laço social (Lacan, 1992), não tendo para si, portanto, delimitação geográfica ou institucional que lhe seja necessária ou exclusiva. Da mesma forma, se o discurso é modalidade de laço, poderíamos também sublinhar que a simples inclusão da psicanálise nos currículos universitários não garantiria em nada a presença do discurso do psicanalista na universidade, com o que nos deparamos com certa complexificação do problema.

Apontamos, por agora, que é preciso ao menos reconhecer que, apesar de seus muitos limites, a universidade brasileira, especialmente a pública, se constitui como importante espaço reconhecido de produção na cultura, o que marca a pertinência de, apesar dos impasses, seguirmos sustentando o trabalho em que nela se pode realizar (tem sido inclusive crescente a presença de psicanalistas em cursos 
de Graduação e Pós-Graduação no Brasil). Trata-se aqui de estabelecer algumas linhas de aposta ${ }^{2}$, uma reflexão sobre as vias possíveis para um trabalho referenciado à psicanálise no contexto universitário, bem como os efeitos que disso se recolhem.

Na clínica de nossa Universidade, temos acompanhado o movimento de muitos que, tendo ali chegado como alunos, estagiários, posteriormente empreenderam uma trajetória na psicanálise. Buscaram análise, formação, iniciaram uma prática que prosseguiu e se consolidou. Aliás, parece-nos que, ao menos no Brasil, raros são os psicanalistas que não estabeleceram o contato com a psicanálise através de sua passagem pela universidade. Então consideramos razoável a suposição de que alguma transmissão ali possa ter se dado. Entendemos que mesmo que se o que se pratica na universidade não possa ser qualificado categoricamente de psicanálise, isso não quer dizer que seus efeitos posteriores - clínicos e de formação - não repercutam marcas desta referência, na medida em que ela seja adotada por aqueles que ali trabalham.

\section{A CLÍNICA(-ESCOLA) COMO VIA PRIVILEGIADA DE PESQUISA E FORMAÇÃO}

De que forma, por qual linhas, portanto, pensar uma inserção possível da psicanálise na universidade? A proposição que defendemos aqui é a de que a dimensão clínica é parte fundamental das condições de possibilidade para sustentação deste trabalho.

Primeiramente, trata-se da importância da clínica enquanto experiência do ensinante, que carrega dela os efeitos que marcam seu ensino. Jorge (2006) propõe que, se hoje no Brasil a teoria lacaniana está presente de modo efetivo na universidade, é preciso reconhecer que é da experiência clínica dos analistas que ela retira seu maior vigor. Além disso, apontamos para a diferença que se registra em uma situação de ensino na qual a clínica opera como norte ou proveniência das perguntas e reflexões levantadas, comparativamente àquela em que a teoria revolve sobre si sem o questionamento pela operação clínica que habilita. Consideramos que um ensino desarticulado por completo da dimensão clínica consiste em uma séria descaracterização do saber psicanalítico.

Nessa linha, vislumbra-se também, e especialmente, a função do fazer clínico no processo de formação do aluno e a possibilidade de que algo da proposta psicanalítica se faça valer. Diversos analistas que possuem experiência na atividade de supervisão em clínicas universitárias já se interrogaram acerca da possibilidade de transmissão, pela via da clínica, da psicanálise na universidade. A clínica sob supervisão, como destaca Dias (2003), abre-se como um campo privilegiado para este debate. O confronto com o cotidiano clínico, como aponta Nobre (2000), inaugura um outro campo do saber, não regido, segundo ele, pelas mesmas leis do conhecimento e da razão. Berlinck (2009), por sua vez, situará o método clínico como produtor de um saber resultante de uma prática (em oposição a um modelo baseado em hipótese e contrastação empírica), um saber que não se apresentará como perene, mas como finito, pontual. Encontramos, portanto, um importante ângulo para pensar a problemática trabalhada na seção anterior, acerca das

2 Utilizamos o termo "aposta" nesse trabalho não como uma alusão ao contexto dos jogos de azar ou como referência a uma aleatoriedade, mas ao esforço e ao investimento sério em uma tarefa que, todavia, não goza de uma garantia prévia. relações entre os discursos e o lugar do saber em cada um. Abrir-se-ia, no campo da prática clínica, a possibilidade de estabelecer-se uma relação distinta com o saber, uma outra posição frente a este no contexto universitário, o que também é defendido por Marcos (2011). Uma abertura pela via da clínica, portanto - dadas algumas condições mínimas, tais como a supervisão -, em relação ao imperativo do toutsavoir do discurso universitário.

Nisto, temos no Brasil um contexto favorável: ao mesmo passo em que podemos observar que nos cursos de formação profissional das universidades de muitos países - tais como Argentina, EUA, França e outros da Europa - a prática clínica vai ocorrer num tempo posterior ao do curso de graduação, no Brasil ela acontece durante o próprio curso. Aqui, os cursos de psicologia, em particular, são inclusive obrigados por sua regulamentação a contar com uma clínicaescola e a prática do estágio fará parte da grade curricular do aluno. A tendência das recentes reformas curriculares tem sido de antecipar ainda mais essa prática, de forma que ela ocorra ao longo do maior período possível no percurso acadêmico.

Tendo presentes as posições e hipóteses lançadas acima, vemos desenhar-se com maior clareza o papel da clínica-escola como território de interesse na condução de nossa reflexão e nosso argumento. Se a prática clínica se apresenta como condição de possibilidade para uma eventual transmissão da psicanálise na universidade e em seu horizonte se vislumbra uma produção pontual de outra relação com o saber no contexto universitário, teríamos na clínica-escola um campo fundamental de articulação, de pesquisa e de ensino acerca de nossa temática.

Como adverte Barros (2006), de todas as modalidades oferecidas pelo mercado de psicoterapias, a psicanálise é a única que dirige sua escuta ao sujeito do desejo inconsciente. Ainda que tenha esta posição diferenciada das outras modalidades psicoterapêuticas e marque uma diferença epistemológica com relação aos seus fundamentos teóricos, o que diz respeito à transmissão da psicanálise em clínicaescola coloca-se como um problema. Como passar a técnica analítica para aqueles tão pouco íntimos com a escuta do próprio inconsciente? Maurano (2006) ressalta que, por mais que os Serviços de Psicologia Aplicada (SPAs, como são 
denominadas as Clínicas-Escola em alguns estados) estejam afetados pela psicanálise, a universidade não forma analistas, nem está entre as suas competências a pretensão de fazê-lo. Fernandes (2006) igualmente foi levada a se questionar sobre a transmissão da psicanálise na supervisão a alunos de psicologia que realizam estágio supervisionado. Na medida em que busquemos dar conta, com um mínimo de rigor, do que ali se faz, facilmente percebemos que estamos frente a um campo de extrema complexidade.

Para Jorge e Costa (2005), todos os problemas que a supervisão psicanalítica apresenta no quadro da formação dos psicanalistas são redobrados quando se trata da supervisão no SPA universitário. Para fazer uma discussão desta problemática, vão partir do que consideram uma das principais novidades introduzidas pela Escola Freudiana de Paris: a desinstitucionalização da supervisão, articulada à introdução da categoria de desejo do psicanalista. Como na supervisão nos SPAs, não é possível desconhecer uma certa dimensão de fiscalização das atividades exercidas pelo aluno, o supervisor adotaria uma postura na verdade antipsicanalítica calcada em um saber, o que seria próprio do discurso universitário. Essa postura apoia-se na crença de que existe uma técnica a ser aprendida e de que a tarefa do supervisor seria apontar o que deve ou não ser feito, fiscalizando a competência clínica do supervisando. Podem ocorrer também, em outros casos, supervisões nas quais o supervisor está no lugar de um significante mestre.

De fato, não poucos são os atravessamentos institucionais que tomam lugar na prática inserida em uma clínica-escola, como apontam diversos autores - tais como Pinheiro e Darriba (2010), Darriba (2011) e Marcos (2011). Tratam-se das relações de "fiscalização", das dificuldades na posição do supervisor, da não obrigatoriedade da análise pessoal, da concomitância ou choque entre as posições de clínico e de aluno, da organização formal da estrutura de um estágio, com prescrições atreladas a processos avaliativos, bem como um tempo delimitado e pré-estabelecido para a finalização das atividades. Estes e outros elementos compõem uma série problemática, que coloca em questão a possibilidade da condução de um tratamento guiado pela psicanálise, enfocando, portanto, o desejo, a dimensão do ato e a estrutura de uma temporalidade retroativa, não prescrita.

Apesar disso, Jorge e Costa (2005) reconhecem que, para alguns, ocorre ali o início de uma prática verdadeiramente analítica. Nesses casos, eles depreendem ter havido o exercício de uma prática que produziu efeitos analíticos.
Também os autores supracitados assumem posição similar, como, por exemplo:

entendemos que, para além da evidência dos impasses existentes, é preciso se perguntar qual é a clínica possível, a partir da psicanálise, neste contexto. Até porque tal clínica, que se organiza em torno do nome da psicanálise, mostra-se relevante em seus efeitos junto a pacientes e estagiários: seja em termos do estabelecimento do desejo de inserção no campo da psicanálise, seja em termos da confirmação deste desejo, quando já previamente manifestado, ou, ainda, nas transformações subjetivas apresentadas pelos estagiários e pelos pacientes. (Pinheiro \& Darriba, 2010, p. 47)

Renova-se, com isso, o interesse no trabalho da psicanálise em contexto de clínica-escola, na medida em que dessa prática se recolhem efeitos cuja desconsideração, a nosso ver, prestaria um desserviço a ambos os campos.

Mais além, julgamos pertinente ressaltar um elemento que provém de nossa experiência institucional na clínica-escola da UFRGS, e que dialoga com alguns destes estudos citados, no que tange aos atravessamentos da instância e da lógica acadêmicas na prática clínica dos estudantes. Tanto o estudo de Darriba (2011) quando o de Pinheiro e Darriba (2010) têm como ponto fundamental de análise o término obrigatório do período de estágio, momento no qual se argumenta que "os impasses advindos da diferença entre o lugar do estudante na universidade e o lugar do analista na clínica são mais facilmente localizáveis" (Pinheiro \& Darriba, 2010, p.47). Nesse momento de encerramento obrigatório, eles indicam a possiblidade de trabalhar as distinções entre discurso universitário e discurso do psicanalista na postura do clínico frente ao que aí emerge da ordem do impossível de saber - ou o que disto se veste de impotência pelo discurso universitário. Trata-se de uma importante contribuição para nosso campo de debate. Todavia, trazemos o que se apresenta como outro verso desta problemática: há vários anos, temos oferecido, para aqueles que se sentirem convocados e manifestarem seu desejo a partir de sua prática, a possibilidade de dar continuidade a seus atendimentos e a suas atividades pela via de um projeto de extensão, bem como de cursos de pós-graduação latu e stricto sensu e envolvimento em pesquisa clínica. Com isso, apontamos também para o fato de que, para além da prescrição burocrática de um período, encontramos também, na própria organização da universidade, formas que permitem algo de um relançamento do desejo do aluno-estagiário-clínico frente a sua prática inicial, caso se sinta convocado a tal.

\section{A INFLEXÃO COMO PRODUTO DA PRÁTICA CLÍNICA SUPERVISIONADA}

Destacaríamos neste ponto da discussão um fenômeno que consideramos de extrema relevância: uma mudança na posição do estudante, uma inflexão (Kessler, 2009), quando inicia sua prática clínica no contexto da clínica-escola na universidade, a qual não raro acaba por tornar-se uma atividade privilegiada. Anos após, muitos são os que vêm a reconhecer que foi por este intermédio que se deu sua via de entrada na formação psicanalítica, o que se encontra em consonância com a aposta de Figueiredo (2008) na possibilidade de ir além da posição de um saber sobre a 
psicanálise na graduação universitária mediante a prática clínica.

Sternick (2006) vai assim mencionar que, chegado o momento de o aluno atender, um outro espaço é aberto, o da clínica do aluno. Sustenta que, enquanto para alguns alunos há ensino, para outros haveria transmissão. Aqueles que conseguem escutar a psicanálise e são capturados pela teoria serão os que pedirão, a posteriori, na clínica da universidade, para serem supervisionados pelo professor-psicanalista, procurando exercer com este o que, para eles, pode ser o primeiro momento da psicanálise no espaço da supervisão.

Ao longo do período de estágio, várias são as mudanças que identificamos na postura daqueles que iniciam sua clínica - mudanças essas que propomos pensar como produto disso que referimos como inflexão. Trata-se da busca de análise pessoal; da intensificação do estudo da psicanálise, agora motivado pela angústia e questionamentos decorrentes de sua prática; por fim, no horizonte, trata-se também do processo mesmo de ratificação ou retificação da escolha pela psicanálise.

A introdução à prática clínica coloca com frequência em xeque aquilo que antes o estudante julgava saber, apresentando-lhe um novo campo em que entra em jogo a hiância entre a apreensão (por vezes superficial) de um conceito teórico e a condução de um tratamento, seus imprevistos, seus impasses e suas surpresas. Frente a isso - esse contato com o não saber -, cabe a ele (auxiliado por alguns outros) a decisão acerca de como se posicionar. Nessa experiência, portanto, é recorrente e desejável que algo claudique na relação do estudante com o saber. Será a partir desta claudicação e seus efeitos que se abrirá uma via possível de trabalho consonante com a ética da psicanálise, bem como o prosseguimento de uma formação analítica no horizonte.

Haveria, contudo, que ressaltar a particularidade de cada percurso de formação: existem alunos que já se encontram em análise mesmo antes de ingressarem na universidade; existem alunos que buscam um tratamento analítico após este ingresso, mas antes de iniciarem uma prática clínica; existem alunos para os quais a necessidade deste tratamento se apresenta em função do início ou do decurso de seu estágio; por fim, há alunos que não buscam uma escuta em qualquer desses momentos. Da mesma forma, a relação com o estudo da psicanálise encontra nuances não desconsideráveis ao longo da formação de cada aluno. A consideração de tais especificidades abre o campo para pensarmos não a partir de generalizações, mas sim na perspectiva de uma tessitura, de efeitos de entrelaçamento que comporiam cada percurso, singular, de formação. Todavia, parece-nos importante demarcar que, compondo a singularidade de cada percurso de formação, a prática clínica detém, como dissemos, a potência de inaugurar um espaço outro, de habilitar uma série de questionamentos e reflexões distintos daqueles que até ali tomaram lugar, na graduação ou fora dela. Isto pelo fato de que - se tudo der certo, diríamos -, não se trata ali da mesma posição subjetiva. Proporíamos também, portanto, diferenciar, em termos de posições distintas, a do aluno e a do clínico. Na primeira, consonante com o discurso universitário, a falta no saber remontaria a uma impotência, e não a uma impossibilidade, posição guiada pelo mandato de um saber todo. Na segunda, operar-se-ia ao menos o começo de um giro, tornando-se a prática a proveniência não apenas dos questionamentos do iniciante, mas também de um saber a ser construído na dimensão, como aponta Berlinck (2009), do particular e do pontual - marcado, portanto, pela transferência.

Enfim, retomando nosso argumento, dá-se para muitos (ainda que obviamente não para todos), no decorrer dos princípios de sua clínica, um ponto de torção, em que se coloca em questão a dimensão do saber. Segundo Kessler (2009):

Clinicar introduz uma inflexão, mudando a postura de uma eventual percepção de auto-suficiência do aluno, que passa a reconhecer a possibilidade de buscar uma formação com aqueles que, anteriormente, podia até procurar desafiar e menosprezar. $\mathrm{O}$ estudante pode pensar que sabe (posição de arrogância universitária), ou mesmo questionar o mestreprofessor (posição histérica). Frente à prática do estágio, isso vira. Como vimos também na bibliografia, a posição da angústia do praticante que inicia é radicalmente distinta da do estudante de graduação (p.114).

Nisto, vemos também desenhar-se a função da supervisão na sustentação da operação que aqui descrevemos. Dias (2003) recorda-nos que a prática da supervisão também implica uma demanda de saber: sobre a teoria, o caso, o diagnóstico, o manejo da transferência, sobre questões supostamente técnicas, questões referentes à eficácia da psicanálise e, até mesmo, demandas de reconhecimento. Quando estas questões se particularizam e são endereçadas a um determinado supervisor, a quem se supõe saber, colocase em jogo a dimensão da transferência. Nesse enquadre, abre-se caminho para considerar que é a partir do manejo do supervisor em questão que se definirão os destinos dessa prática $^{3}$. A falta de saber poderá, na supervisão, funcionar como causa, tanto para o aluno quanto para o supervisor, onde a sustentação da dimensão do enigma abre a possibilidade de verificação da produção de um saber singular. Nesse espaço de palavra, pode emergir a disjunção entre o saber constituído e o saber que se constrói, constituindo um lugar privilegiado de operação com o saber e a verdade.

3 O uso da denominação "analista supervisor" (Nobre, 2000, p.95), nos indica uma interessante direção de trabalho, uma vez que denota um percurso de formação analítica da qual os supervisandos, via de regra, não partilham. Assim, também a trajetória do analista supervisor entraria em jogo como elemento de importância na sustentação de um trabalho eventualmente consoante à psicanálise. 
Como apontam Barros e Oliveira (2003), a supervisão desempenha importante papel na possibilidade do "aprender a partir da psicanálise" (p. 177) - expressão utilizada por Freud - na universidade. Só aí se poderia fazer um "furo no saber como semblante que marca o discurso universitário" (Figueiredo, 2008, p. 247), sendo, desta forma, "fundamental para fazer operar o giro nos discursos" (Figueiredo, 2008, p. 247).

Apresenta-se, com isso, uma importante distinção entre o trabalho de ensino que se estabelece em sala de aula e aquele que toma lugar no espaço de supervisão - como também apontam Figueiredo e Vieira (2000). Para as autoras, ao passo que o primeiro levaria no máximo a um saber sobre a psicanálise, no segundo o ensino da psicanálise seria menos fundado sobre a apreensão de seus conceitos do que sobre a experiência singular do trabalho analítico. O supervisor trabalha sobre os efeitos produzidos pelas intervenções do clínico, reconhecendo e sustentando seu ato, bem como abrindo espaço para uma elaboração de saber acerca destes efeitos. Também para Marcos (2011), em oposição à aplicação de um saber, "a supervisão abriria espaço, então, para a possibilidade de uma prática que leve à produção de saber" (p. 208). Seria então exatamente nesse encontro com a clínica pela via do ensino, emergindo ao mesmo tempo o saber e a falta, que poderia existir uma possibilidade de transmissão de um saber psicanalítico (Figueiredo \& Vieira, 2000).

Eis uma função possível da supervisão clínica na inserção da psicanálise na universidade: operar um giro discursivo a partir do que claudica na relação entre aquele que inicia sua prática e o ideal de um saber completo, que daria conta de seu fazer. Tomar o tropeço do aluno, quando este percebe não poder oferecer uma resposta préfabricada àqueles que escuta, e fazer operar aí o impossível ao qual se dirige o discurso do analista, em oposição à pressuposição universitária da impotência. Trazer à baila, portanto, justamente o limite do saber, o impossível do tout-savoir sustentado pelo discurso universitário, e disto extrair consequências clínicas, sublinhando seu caráter particular, pontual, construído a partir da transferência. O sucesso desta aposta carrega consigo um conjunto não desconsiderável de efeitos no percurso de formação daqueles que, iniciando seu percurso, se propõem a sustentá-la.

\section{CONCLUSÃO}

Neste trabalho, situamo-nos no campo mais amplo de debate acerca das relações entre psicanálise e universidade, temática que se constitui há anos como terreno de impasses em função da disparidade entre os modelos e lógicas de formação em jogo. Procurando ocupar uma posição que evite a afirmação categórica de um universal, seja ele positivo ou negativo (a relação entre psicanálise e o contexto universitário não seria, a priori, necessária, natural, ou impossível), posicionamo-nos desde uma pergunta pelas vias possíveis de transmissão da psicanálise no contexto universitário, mesmo que pontuais, a serem constatadas em um momento posterior. Neste texto, enfocamos a prática clínica supervisionada na universidade como via privilegiada para tal, tendo a clínicaescola como cenário e tomando como balizas os efeitos recolhidos de nossa experiência neste contexto.

Nossa reflexão trouxe como base a teoria dos quatro discursos proposta por Lacan (1992), tendo a diferença entre o discurso universitário e o discurso do analista operado como ponto fulcral de nosso argumento. Nesta diferença, posicionamos a ênfase na distinção do lugar do saber entre os dois discursos: ao passo que o primeiro colocaria sua mira em um "tudo saber", o segundo apontaria para a impossibilidade radical desta pretensão. Disso depreendemos a posição do universitário - e do aluno, por extensão - em contraste com aquela que seria a do analista: o primeiro veste de impotência aquilo que o segundo reconhece como o impossível a partir do qual opera.

No campo assim estabelecido, defendemos a proposição de que a dimensão clínica é parte fundamental das condições de possibilidade para sustentação de um trabalho consoante com a psicanálise na universidade. Nisto, resolvemos enfatizar os efeitos da prática clínica do estudante. Procuramos demonstrar os efeitos dos princípios de um trabalho clínico naquele que até então deparava-se com a psicanálise apenas em sala de aula. Como vimos, por vezes se produz aí o que chamamos de inflexão - um giro de posição por parte do estudante (frente ao saber, a sua prática, aos professores/supervisores, etc.). Uma operação, calcada na experiência clínica, e balizada pela atividade de supervisão, de registro como tal do que se apresenta como impossível - impossível de saber - e de habilitação de uma prática a partir do reconhecimento deste impossível. Romper-se-ia, com isto, mesmo que pontualmente, com a posição outorgada pelo discurso universitário, em que o impossível de saber é tomado como impotência (Darriba, 2011). Assim, por pontual que seja esse momento, apontamos para a possibilidade de que daí decorram efeitos que, a posteriori, levem a uma busca por dar continuidade a uma formação analítica, caso $o$ estudante se sinta convocado a tal. 


\section{REFERÊNCIAS}

Barros, R. M. M. (2006). A psicanálise e sua transmissão: da supervisão em clínica-escola. In S. Alberti, \& A. C. Figueiredo (orgs.). Psicanálise e saúde mental: Uma aposta. (pp. 191-8). Companhia de Freud.

Barros, R. M. M., \& Oliveira, G. F. T. (2003). Efeitos analíticos da supervisão na universidade. Escola Letra Freudiana $-A$ análise é leiga - da formação do psicanalista, 22 (32), 175-80.

Berlinck, M. T. (2009). Saber clínico e saber teórico. Rev. Latinoam. Psicopat. Fund., 12 (2), 259-262.

Castro, J. E. (2006). O ensino de Lacan e a ética da psicanálise. In A. C. Lo Bianco (Org.). Freud não explica: A psicanálise nas universidades. (pp. 97-115). Contracapa.

Coutinho, D. M. B., Mattos, A. S., Monteiro, C. F. A., Virgens, P. A., \& Almeida Filho, N. M. (2013). Ensino da psicanálise na universidade brasileira: Retorno à proposta freudiana. Arq. bras. psicol., 65 (1), 103-120.

Darriba, G. A. (2011). O lugar do saber na psicanálise e na universidade e seus efeitos na experiência do estágio nas clínicas-escola. Ágora (Rio de Janeiro), 14 (2), 293-306.

Dias, L. M. (2003). A questão da transmissão e da supervisão na universidade. A análise é leiga: Da formação do psicanalista, XXII (32), 167-73.

Fernandes, A. H. (2006). Sobre a transmissão da psicanálise na supervisão. In S. Alberti, \& A. C. Figueiredo (Orgs.). Psicanálise e saúde mental: Uma aposta. (pp. 169-76). Companhia de Freud.

Figueiredo, A. C. (2008). Psicanálise e universidade: Reflexões sobre uma conjunção ainda possível. Fractal Revista de Psicologia, 20 (1), 237-52.

Figueiredo, A. C., \& Vieira, M. A. (2000). A supervisão: Do saber sobre a psicanálise ao saber psicanalítico. Cadernos do IPUB, 9, 84-92.

Fonteles, C. S. L. (2015). Psicanálise e Universidade: uma análise da produção acadêmica no Brasil [Tese de Doutorado]. Universidade Federal da Bahia / Université Paris Diderot (Paris 7), Salvador/Paris.

Fontenele, L. (2006). Inserção e recepção da psicanálise no curso de psicologia da UFC. In S. Alberti \& A. C. Figueiredo (Orgs.) Psicanálise e saúde mental: Uma aposta (pp. 177-83). Companhia de Freud.

Freud, S. (1976). Deve a Psicanálise ser ensinada na universidade? (J. Strachey, Ed., E. A. M. Souza, Trad.) In S. Freud Edição Standard Brasileira das Obras Psicológicas Completas de Sigmund Freud (pp. 217-219). Imago. (Trabalho original publicado em 1919).
Jorge, M. A. C. (2006). Jacques Lacan e a renovação da clínica analítica. Sobre o impacto de seu ensino no Brasil. In M. A. C. Jorge (Org.). Lacan e a formação do psicanalista (pp. 195202). Contracapa.

Jorge, M. A. C., \& Costa, T. (2005). Entre supervisão e controle: A psicanálise no SPA da universidade. In S. Altoé \& M. M. Lima (Orgs.). Psicanálise, clínica e instituição. (pp. 241-259). Rios Ambiciosos.

Kessler, C. H. (2009). A supervisão e a clínica escola: o ato no limite do discurso [Tese de Doutorado]. Universidade Federal do Rio de Janeiro, Rio de Janeiro.

Lacan, J. (1992). O seminário, livro 17: O avesso da psicanálise. Jorge Zahar.

Lemaire, A. (1979). Jacques Lacan: Uma introdução. Campus.

Lo Bianco, A. C. (2003). Sobre as bases dos procedimentos investigativos em psicanálise. Psico-USF, 8 (2), 115-23.

Lo Bianco, A. C. (2006a) Psicanálise e universidade: a questão da filiação do analista. In: A. C. Lo Bianco (org.) Freud não explica: A psicanálise nas universidades (pp. 21-27). Contracapa.

Lo Bianco, A.C. (2006b). O ato no texto analítico: Significação e autorização. Estilos da Clínica, 9 (21), 48-55.

Lo Bianco, A. C., \& Sá, R (2006). A objetividade do experimento: A elisão do sujeito e de seu ato. In A. Bastos (Org.) Psicanalisar hoje (pp. 67-78). Contracapa.

Marcos, C. M. (2011). Reflexões sobre a clínica-escola, a psicanálise e sua transmissão. Psic. Clin., 23 (2), 205 - 220.

Maurano, D. (2006). Um estranho no ninho ou a psicanálise na universidade. In M. A. C. Jorge (Org.). Lacan e a formação do psicanalista (pp. 209-227). Contracapa.

Nobre, L. (2000). Da demanda de conhecimento à abertura ao saber - considerações sobre a prática da supervisão na universidade. Cadernos do IPUB, 9, 93-8.

Orejuela, J., \& Salazar, V. (2009). Entrevista a Jean Allouch. Revista Cientifica Guillermo de Ockham, 7(2), p. 161-167.

Pinheiro, N. N. B., \& Darriba, V. A. (2010). A clínica psicanalítica na universidade: reflexões a partir do trabalho de supervisão. Psic. Clin., 22 (2), 45 - 55.

Roudinesco, E. (2000). Por que a psicanálise? Jorge Zahar.

Sbano, V. (2004). Ensino de psicanálise nas universidades [Tese de Doutorado]. Universidade Federal do Rio de Janeiro, Rio de Janeiro.

Sternick, M. V. C. (2006). Da intenção da transmissão à extensão da clínica psicanalítica na universidade. In S. Alberti \& A. C. Figueiredo (Orgs.) Psicanálise e saúde mental: Uma aposta (pp. 185-9). Companhia de Freud. 